\title{
REPRESENTAÇÕES SOCIAIS DE LAZER E TEMPO LIVRE DE ADOLESCENTES: DUALIDADES SEM DESCOMPASSO
}

\author{
REPRESENTACIONES SOCIALES DE OCIO $\Upsilon$ TIEMPO LIBRE ENTRE \\ ADOLESCENTES: DUALIDADES SIN DESAJUSTE
SOCIAL REPRESENTATIONS OF LEISURE AND FREE TIME AMONG ADOLESCENTS: DUALITIES WITHOUT MISMATCH

\author{
Elisa Fabris de Oliveiraa ${ }^{1} 2$ e Edinete Maria Rosa $^{1}$ \\ ${ }^{1}$ Universidade Federal do Espírito Santo, Vitória/ES, Brasil \\ ${ }^{2}$ Faculdade de Ensino Superior de Linhares, Vitória/ES, Brasil
}

\begin{abstract}
RESUMO: O objetivo deste estudo foi identificar e compreender as representações sociais de lazer e tempo livre de adolescentes de classe média de Vitória-ES. Participaram da investigação 21 estudantes, de 14 a 17 anos, divididos em quatro grupos, submetidos à técnica do grupo focal e à análise de conteúdo. Observou-se que as representações dos adolescentes se ancoram, principalmente, nos valores sociais vigentes, estando as noções de produtividade, prioridade ao estudo e descanso compensatório bastante presentes. Constatou-se também que as representações de lazer se constituem de vivências positivas e saudáveis, tais como a socialização entre pais e amigos e a prática de atividades esportivas.
\end{abstract}

PALAVRAS-CHAVE: Adolescentes; Classe média; Lazer; Tempo livre.

RESUMEN: El objetivo de este estudio fue identificar y comprender las representaciones sociales de ocio y tiempo libre de adolescentes de clase media de Vitória-ES. Participaron de la investigación 21 estudiantes, de 14 a 17 años, divididos en cuatro grupos, sometidos a técnica del grupo focal y a análisis de contenido. Se observó que las representaciones de los adolescentes se anclan, principalmente, en los valores sociales vigentes, estando las nociones de productividad, prioridad al estudio y descanso compensatorio bastante presentes. Se constató también que las representaciones de ocio presentan vivencias positivas y saludables, tales como la socialización entre padres y amigos y la práctica de actividades deportivas.

PALABRAS CLAVE: Adolescentes; Clase media; Ocio; Tiempo libre.

ABSTRACT: The purpose of this study was to identify and understand the social representations of leisure activities and free time of middle-class adolescents from Vitória-ES. Twenty-one students from 14 to 17 years old were divided into four groups and submitted to focal group technique and content analysis. It was observed that the representations of adolescents are anchored, mainly, in the current social values, being the notions of productivity, priority to study and compensatory rest quite present. It was also observed that the representations of leisure present positive and healthy experiences, such as the socialization between parents and friends and the practice of sport activities..

KEYWORDS: Adolescents; Middle-Class; Leisure; Free Time. 


\section{Introdução}

O presente estudo teve como objetivo conhecer um pouco mais os adolescentes de classe média por meio de suas representações sociais de lazer e de tempo livre. Optou-se por ter como objeto de investigação esses fenômenos cotidianos, considerando que é nas horas livres que "os jovens têm encontrado sua forma de estar-no-mundo, gerando práticas próprias, seguindo modas e padrões de consumo singulares, criando estilos e culturas" (Franch, 2000, p. 7). O lazer e o tempo livre apresentam-se, assim, como as esferas ideias para se aproximar desses sujeitos, compreendendo suas identidades, vivências, sociabilidades, visões e experiências de mundo.

Para a realização da pesquisa, buscando romper com a noção histórica de negatividades associadas aos jovens e adolescentes, e os reconhecendo como protagonistas sociais - que apresentam características comuns, mas também são diversos e se constituem em harmonia com o contexto (Abramo, 2008; Chimeli, Nogueira, Pimenta, \& Schall, 2016) -, escolheu-se dar ouvido a eles próprios, através de discussões pouco direcionadas em grupos focais.

O tema do lazer e do tempo livre juvenil ainda é incipiente. No âmbito da Psicologia, um levantamento de teses e dissertações sobre adolescência e juventude publicadas entre 2006 e 2011 identificou que somente oito estudos (1,66\%) investigaram temáticas relacionadas ao esporte, à cultura e/ou ao lazer (Stengel \& Dayrell, 2017). Outros trabalhos frequentemente dedicam-se a problemáticas que abarcam a esfera do tempo livre - tais como nos estudos sobre drogas, sexualidade e consumo de novas tecnologias (Franch, 2000) -, contudo, nesses casos, o fenômeno é assumido apenas como variável secundária e não como o objeto de pesquisa.

Apesar da produção ainda reduzida, é possível observar que os estudos realizados já trazem importantes contribuições, tanto no que se refere à abordagem do desenvolvimento, quanto no âmbito da psicologia social (Bonato, Sarriera, \& Wagner, 2012; Martins, Trindade, Menandro, \& Nascimento, 2014; Nodari, Rosa, Nacimento, \& Guerra, 2016). Com certa recorrência, verifica-se que o lazer e o tempo livre são percebidos como menos importantes em relação ao estudo e ao trabalho, e, por isso, aparecem significados como momentos de compensação e de descanso, meramente com a finalidade de propiciarem a manutenção da produtividade (Oliveira \& Rosa, 2016). Por outro lado, as potencialidades associadas a eles também são reveladas. Sabe-se da sua importância para o desenvolvimento de autonomias, de criatividade e de aprendizagem das normas sociais (Brenner, Dayrell, \& Carrano, 2008).

As diversidades associadas a sua prática também aparecem de forma recorrente, apontando a influência dos contextos, da cultura e do acesso a infraestruturas e tecnologias para sua vivência (Brenner et al., 2008). Nesse sentido, muitas investigações têm optado por estudar de forma específica e delimitada os diversos grupos sociais quando se trata da temática (Franch, 2000; Martins et al., 2014; Nodari et al., 2016). As divergências na sua vivência quando analisada por gênero, por exemplo, revelam como na prática e na significação as delimitações do lazer e do tempo livre feminino diferem das masculinas. As consequências das desigualdades históricas refletem-se na limitada circulação das meninas nos espaços públicos, na escassa prática de esporte por elas (Nodari et al., 2016; Oliveira, Nodari, \& Rosa, 2018) e na frequente dificuldade para superarem os estereótipos de fragilidade e delicadeza (Oliveira \& Rosa, 2016). 
Nesse sentido, reconhecendo a importância do contexto para o presente objeto de estudo, a investigação optou por estudar adolescentes de uma classe econômica e social específica: a classe média. O interesse por esse grupo teve origem no fato dele representar, frequentemente, o padrão, o modelo a ser seguido pelas classes populares; e, mesmo assim, no Brasil, nos últimos anos, serem um grupo menos estudado (Abramo, 2007, 2008).

Além disso, historicamente, os adolescentes de classe média foram sinônimos da concepção de adolescência e juventude (Abramo, 2007), e atualmente apresentam características que estimulam a investigação sobre suas representações sobre lazer e tempo livre; sabe-se que eles constantemente são poupados do trabalho formal e de responsabilidades domésticas; e que possuem acesso facilitado a novas tecnologias e a entretenimentos virtuais e eletrônicos (Oliveira, Nodari, \& Rosa, 2018). Todavia, pouco se sabe sobre o que o lazer e o tempo livre significam para eles e quais as consequências dessas significações para as suas práticas e desenvolvimento. Foi buscando parte dessa compreensão que realizou-se a presente pesquisa.

Mas, afinal, o que seria o lazer e o tempo livre? Segundo Elias e Dunning (1992), eles são dois fenômenos distintos, que se constroem junto à sociedade, sendo típicos de cada cultura e organização social. Para os autores, o lazer e o tempo livre que conhecemos hoje são frutos do processo civilizatório, da monetarização do tempo e da necessidade humana de extravasamento emocional. O lazer ocorre nos momentos de liberdade de expressão, possibilitando o rompimento das rotinas através de sensações agradáveis, vindas da prática de atividades com pouca vigilância social de comportamento, como por meio do esporte. Já o tempo livre seria uma esfera temporal, que permite a vivência de atividades diversas, que vão desde o lazer até o semilazer - práticas com menor extravasamento emocional, mas com percepção positiva pelos que as executam (Bonato et al., 2012; Elias \& Dunning, 1992).

Munné e Codina (1992) acrescentam a essas definições as noções de auto e heterocondicionamento. Para eles, determinismos sociais influenciam na prática do lazer e do tempo livre - heterocondicionamentos -, mas o nível dessas interferências é variável. Eles explicam que o lazer ocorre somente quando o autocondicionamento - a vontade do próprio indivíduo - prevalece, e ele mesmo percebe a prática como uma escolha livre.

A Sociologia do Lazer nos direciona para uma primeira compreensão do que seria o lazer e o tempo livre, mas ainda nos falta entender como adolescentes significam, compartilham ideias e orientam suas práticas quando se tratam desses fenômenos. Assumindo tal problemática como o foco da investigação, optou-se por adotar a Teoria das Representações Sociais (TRS).

Esse aporte teórico, que possibilita a investigação do senso comum considerando sua origem nas relações grupais (Jodelet, 2011 ; Moscovici, 1978, 2003), permitiu identificar os elementos que sustentam a ideia compartilhada por adolescentes de classe média sobre o lazer e o tempo livre, e entender de forma contextualizada suas interpretações, vivências, ancoragens e objetivações (Moscovici, 2003). A TRS possibilita o estudo de fenômenos e de objetos sociais a partir da noção comum e compartilhada pelos diferentes grupos sociais, buscando a realidade que os orienta. Com o objetivo de se conhecer como adolescentes de classe média compreendem e vivem o lazer e o tempo livre - e seguindo orientação de estudo anterior (Oliveira \& Rosa, 2016) -, entende-se que a teoria se apresentou como um suporte adequado para o presente estudo. 
Segundo Moscovici (2003), as representações sociais são um tipo de conhecimento da sociedade moderna que possibilita entender como um determinado grupo compartilha significados de fenômenos que, a princípio, lhes eram pouco familiares. Essas representações podem ser descritas como uma realidade própria, que possibilita a compreensão do novo a partir de outros conhecimentos já dominados e de fácil assimilação.

As representações sociais estão ligadas ao contexto social, à época e ao grupo que as compartilha. Por outro lado, elas atuam ativamente na formação desses sujeitos, na orientação de suas práticas e na interpretação que eles fazem do mundo (Jodelet, 201 1; Nóbrega, Andrade, \& Melo, 2016). Portanto, as representações sociais devem ser entendidas como um conhecimento que ao mesmo tempo em que é dinâmico e está suscetível a mudanças, é construído no decurso do tempo e se reflete como o resultado de várias gerações; ele constrói a sociedade e constrói-se a partir dela, em um movimento duplo de produto e processo (Moscovici, 2003).

Para se constituírem, as representações dependem da ancoragem e da objetivação. A ancoragem caracteriza-se por dar sentido a um objeto não familiar, através de outros conhecimentos já existentes, organizados e categorizados de acordo com os padrões e os valores vigentes. Já a objetivação refere-se à face figurativa da interpretação, dando materialidade a uma ideia abstrata e tornando-a mais compreensível e concreta (Moscovici, 2003). Sobre a estrutura dessas representações, Abric (2001) propõe que elas se organizam por meio de um núcleo central e de um sistema periférico. Esse núcleo, que reúne as principais representações, caracteriza-se por ser pouco mutável e historicamente constituído. Já o sistema periférico é formado por representações que se formam a partir do contexto, sendo adaptável à realidade momentânea e às experiências de cada indivíduo. Nesse sentido, reforça-se o modo pouco homogêneo de formação das representações sociais - marcado por tensões e conflitos entre os saberes - e sua gênese dinâmica, complexa e sociocognitiva (Nóbrega et al., 2016).

\section{Método}

\section{Participantes}

A amostra do estudo foi formada por 21 adolescentes, com idades entre 14 e 17 anos, que não trabalham; estudam no ensino médio em duas escolas particulares de Vitória - ES; e que realizam atividades extraclasse - tais como esportivas e de língua estrangeira. A escolha das instituições de ensino deu-se por conveniência e respeitou o objetivo de investigar adolescentes de classe média. As escolas localizam-se em bairros nobres da cidade, apresentam mensalidade elevada, mas não se caracterizam como as mais tradicionais da região. Além disso, possuem número limitado de alunos e são conhecidas por terem um projeto pedagógico que vai além do vestibular.

Os participantes do estudo foram divididos em quatro grupos e serão apresentados a seguir por meio de códigos. Fizeram parte do grupo 1 cinco participantes: quatro meninos - G1P1, G1P3, G1P4 e G1P5 - e uma menina - G1P2. O grupo 2 foi formado por quatro meninas - G2P1, G2P2, G2P3 e G2P4 -; e o grupo 3 contou com cinco integrantes, um menino - G3P3 - e quatro meninas - G3P1, G3P2, G3P4 e G3P5. Já no grupo 4 participaram sete adolescentes, três meninos - $\mathrm{G} 4 \mathrm{P} 2$, G4P4 e $\mathrm{G} 4 \mathrm{P} 7$ - e quatro meninas - G4P1, G4P4, G4P5 e G4P6. 


\section{Instrumento e procedimentos de coleta de dados}

Para a coleta dos dados, optou-se pelo uso da técnica do grupo focal, que permite a captação de dados por meio das interações grupais, através da discussão de determinados tópicos definidos pelo pesquisador. O grupo focal tem como objetivo possibilitar a aproximação das compreensões que os participantes possuem acerca desses tópicos e permite conhecer as experiências e perspectivas dos sujeitos estudados. A técnica apresenta-se como uma boa estratégia para estudos em representações sociais, por possibilitar a observação da construção compartilhada do conhecimento e por fazer emergir temas e argumentos que fariam parte de uma conversação em ambiente natural sobre o assunto (Nóbrega et al., 2016; Sá, 1998).

Para a condução dos grupos, utilizou-se um roteiro com temas de discussão sobre rotinas dos participantes; conceitos e caracterização de lazer e de tempo livre; e associação da temática com questões geracionais e de gênero. Os tópicos do roteiro foram elaborados considerando questões recorrentes nos estudos sobre lazer e tempo livre de jovens e adolescentes (Fanch, 2000; Bonato et al, 2012; Oliveira \& Rosa, 2016).

\section{Resultados e discussões}

A análise de conteúdo temática (Bardin, 2007) identificou seis categorias que emergiram dos dados e que serão discutidas e apresentadas separadamente.

\section{Categoria 1 - Tempo livre: tempo sem compromissos ou tempo de obrigação?}

Nesta categoria, foram reunidos os conteúdos que se referiam ao tempo livre através da ideia de tempo sem compromissos ou de obrigação. Inicialmente, verificamos que, para explicar suas ideias acerca do tempo livre, os participantes recorreram ao estabelecimento de relações entre esse tempo e as obrigações presentes em suas rotinas. Contudo, o significado dessas relações foi mudando com o andamento das coletas. As noções expressas no início das discussões sugeriram que, para esses adolescentes, o tempo livre muitas vezes é entendido como aquele tempo que faz um contraponto com as atividades obrigatórias, sendo ele uma folga, um momento sem compromissos: "Uma hora que você não tem nada obrigado para fazer" (G2 $\left.\mathrm{P}_{4}\right)$.

Considerando que entre esses participantes as atividades escolares representam suas obrigações mais significativas, foi possível observar também que o tempo livre foi explicado a partir da ideia de negação às atividades de estudo. Todavia, com o avançar das discussões, essa relação foi assumindo nova configuração; a contraposição entre o tempo livre e as atividades de estudo perderam força, e a associação entre ele e as tarefas obrigatórias passaram a ser expressas a partir de um novo significado. Ao descreverem suas rotinas, os adolescentes passaram a se referir ao tempo livre como um momento próprio para produzir, dar continuidade às tarefas cotidianas e, principalmente, para estudar: "Quando você está no tempo livre, você está fazendo um negócio obrigado, muitas vezes. (G1P3)"; "Na maioria do tempo livre eu estudo ( $\left.\mathrm{G}_{2} \mathrm{P} 2\right)$ ". 
Essa contradição entre as percepções do tempo livre e as atividades obrigatórias chegou inclusive a provocar dúvidas durante o grupo 1. Verificando uma na mudança no percurso das discussões, um dos adolescentes questionou: "O tempo livre de que você está falando é tipo fora do horário escolar, ou tempo livre fora da sua rotina de estudo? ( $\mathrm{G} 1 \mathrm{P} 4)$ ).

Observou-se, assim, que apesar de o tempo livre indicar a princípio liberdade e ausência de obrigações, na prática, ele costuma ser usado para colocar as tarefas em dia e realizar atividades que possibilitem o alcance da produção, tão valorizada pela sociedade contemporânea. Nesse sentido, nesta categoria, percebemos que a compreensão do fenômeno se estabelece essencialmente a partir de duas representações sociais: uma que reflete a ideia de que o tempo livre indica ausência de obrigações; e outra que se refere a um tempo extracurricular, mas que na prática é essencialmente usado para dar continuidade aos estudos e a outras demandas rotineiras.

Elaborando sobre essa dualidade entre apropriação livre do tempo e realização de atividades impostas, o participante $\mathrm{G} 1 \mathrm{P} 2$ afirmou: "O que eu considero tempo livre é só um tempo em que você não tem 'teoricamente' obrigação. Pois na prática você sempre tem alguma obrigação. Você é moldado por valores da sociedade, você sempre está sob alguma obrigação".

Assim, o adolescente questiona se a liberdade de escolha, explícita no termo "tempo livre", seria mesmo possível. Essa ideia pode ser associada com as proposições de Adorno (2002), que reafirma o caráter heterocondicionado do tempo livre e nega a possibilidade de que os modos de vivência desse tempo superarem as demandas e expectativas da sociedade. Com ideia similar, o participante chega a afirmar que em sua visão o tempo livre não existe:

Eu acho que não existe esse tempo livre. Tudo que eu estou fazendo, por mais que eu ache que seja livre... Agora eu parei de estudar, estou livre, vou ver um jornal'. Não! Eu já estou estudando de novo, estou fazendo isso pensando no Enem. ( $\left.\mathrm{G}_{1} \mathrm{P} 2\right)$

A ideia levantada pelo adolescente e pelo seu grupo fornece um direcionamento para a compreensão da contradição inicialmente apontada. O tempo livre é entendido pelos estudantes como um momento em que não se tem uma atividade obrigatória pré-estabelecida, mas que, geralmente, por questões além de seus desejos, acaba absorvendo algumas obrigações. Nesse sentido, a liberdade não parece ser percebida de modo a compor os elementos das representações sociais dos adolescentes. Essa ideia é reforçada por falas que demonstram que, pela vontade deles, o tempo livre seria vivenciado de forma distinta a que costuma acontecer: "Se eu não tivesse que estudar, eu faria alguma coisa que eu goste: sair, ir ao cinema e dormir! ( $\left.\mathrm{G}_{2} \mathrm{P} 2\right)$ ".

Assim, verificou-se que a pressão para que os adolescentes estudem durante o tempo livre é bastante evidente. Refletindo os valores sociais, em um claro processo de ancoragem, os participantes revelaram o quanto sentem que precisam estudar cada vez mais e dedicar o seu tempo livre para a realização dessa atividade. Essa constatação vai ao encontro do que observaram Oliveira e Rosa (2016) em investigação com jovens universitárias, e ao que propõem Aquino e Martins (2007) sobre o paradoxo vivido pelo homem moderno: "devo dedicar-me ao máximo ao trabalho ou buscar me libertar das tarefas e usufruir de um tempo para mim?" 
Com a necessidade de estudo constante, aparece também nas falas dos participantes a noção de "aproveitamento do tempo livre". Reproduzindo e apropriando-se dos valores do sistema capitalista, os adolescentes demonstraram que suas percepções do que seria o "bom" uso do tempo livre estão ancoradas na ideia de produção, de aprendizagem e de realização daquilo que é vivido por eles como atividade de trabalho, o estudo. Nesse processo, observamos a necessidade desses adolescentes de tornarem o tempo livre o mais "produtivo" possível, o que requer atenção em virtude das consequências que esses comportamentos podem provocar.

Por fim, verificamos que as duas principais representações sociais identificadas nessa classe temática também estão relacionadas com o dia da semana. Para os adolescentes, a percepção que adotam acerca do tempo livre altera-se significativamente quando se trata de dias úteis ou de finais de semanas: em alguns dias predomina a sua significação como um momento das atividades obrigatórias e do estudo - dias úteis -, e, em outros, com menor frequência, como momento sem compromisso e próprio para a vivência do lazer sábados e domingos.

\section{Categoria 2 - Tempo livre como momento de descanso e de dormir}

Como consequência da vivência do tempo livre essencialmente por meio de atividades do tipo obrigatória ou rotineira, os adolescentes identificaram que, por necessidade, esse tempo também representa descanso e momento de relaxamento: "Nem sempre o tempo livre tem que ser produtivo. Pode ser só descansar” (G2P3). É importante pontuar, contudo, que quase sempre, especialmente entre os jovens mais novos e de classe média (Nunes, Pires, Azevedo, \& Hutz, 2014), o tempo livre como descanso veio acompanhado do tempo livre como estudo. Essa recorrência reflete que possivelmente o primeiro seja consequência da pressão e do cansaço gerados pelo segundo, que acaba provocando necessidade de "recarregamento" das energias.

O tempo livre como descanso parece, portanto, ter uma dupla função: possibilitar um momento de repouso e de folga das tarefas obrigatórias, e proporcionar recursos físicos e mentais que permitam que as atividades produtivas possam ser retomadas com vigor. Além disso, a compreensão do descanso vem acompanhada do próprio cansaço, e configura-se como uma necessidade fisiológica que se apresenta como uma obrigação (Elias \& Dunning, 1992): "Eu descanso, mas eu acho que até o descansar é obrigatório" (G1P2).

Essa obrigação está ancorada nas noções de valorização do trabalho e das atividades entendidas como produtivas, de modo que o descansar assume o sentido de pausa para recomposição e volta ao "trabalho". A ideia foi inicialmente compartilhada pela sociedade industrial, aquela que formalmente estabeleceu o tempo livre e a regulamentação das jornadas de trabalho - em função das constantes lutas e reivindicações (Cardoso, 2007) e do seu interesse em manter o nível da produção -, mas ainda segue em vigor (Aquino \& Martins, 2007).

As discussões também revelaram que as representações sociais de tempo livre para os estudantes compreendem a atividade dormir - bastante citada nos grupos. O dormir, apesar de parecer sinônimo do descansar, nas falas dos adolescentes adquiriu sentido particular. Para eles, nem o dormir significa necessariamente descansar e nem o descansar está diretamente ligado ao dormir. O descansar refere-se a um repouso mental e físico que pode ser realizado de diferentes formas, desde que seja percebido como um momento de 
escape da rotina de estudo e da fadiga ocasionada por ela. Ele seria um estado, e não necessariamente uma atividade ou a ausência de todas elas: "(O tempo livre) é você descansar fazendo alguma coisa, sem compromisso (G1P5)".

Por outro lado, o dormir aparece como uma atividade em si mesma, um modo de aproveitamento do tempo livre muito realizado pelos participantes. É claro que a forte presença dessa atividade e de sua importância para a representação social de tempo livre está associada a alguns sintomas sociais, fisiológicos e ao hábito de dormir tarde e, portanto, pouco (Amra et al., 2017; Capelini \& Dias, 2017). Todavia, faz-se necessário dar atenção à questão, uma vez que os adolescentes percebem que nesse contex to o dormir pode assumir o caráter de vício, de prática automatizada e de perda de tempo, assim como o jogar computador e videogame e o assistir à TV: "Eu tento não dormir de tarde, mas eu acabo sempre dormindo... Eu acho que dormir à tarde cria um ciclo vicioso, você... não dá para sair disso" (G3P5).

Portanto, observou-se que o descansar e o dormir são elementos fundamentais para a representação social de tempo livre para os adolescentes investigados, e a sua relevância está embasada nos valores, no estilo de vida e na prática dos sujeitos investigados: realizam muitas atividades extracurriculares, usam o tempo livre com atividades obrigatórias, sofrem pressões quanto à manutenção da produtividade do estudo e apresentam hábitos que frequentemente estão associadas ao prejuízo do sono - acordar cedo, dormir tarde e fazer uso frequente de telas por meio de smartphones e tablets (Amra et al., 2017; Capelini \& Dias, 2017; Nunes et al., 2014).

\section{Categoria 3 - Lazer como bem-estar, prazer e diversão}

Sobre o lazer, observamos que sua compreensão está essencialmente associada às sensações agradáveis percebidas e sentidas durante sua vivência. Os adolescentes, mais que delimitarem atividades características do lazer, referiram-se ao fenômeno através do tipo de sensações que ele pode proporcionar e do que o torna diferente das atividades rotineiras. Dessa forma, verificamos que o "bem-estar", o "prazer" e a "diversão" são importantes elementos das representações sociais de lazer para os participantes do estudo, e juntos traduzem a significação da sensação do lazer: "Lazer é se sentir bem, ter prazer e se divertir" (G2P3); "É um tempo para você fazer o que você gosta... Qualquer coisa que te dê prazer!" (G3P5).

A importância conferida pelos participantes às sensações de prazer e de diversão encontra-se amparada em pesquisas anteriores. Elias e Dunning (1992) já afirmavam que a principal definição de lazer deve ser entendida a partir da excitação: sensação positiva de extravasamento emocional que algumas atividades tendem a proporcionar às pessoas, podendo sua intensidade ser maior ou menor de acordo com o contexto vivenciado. O termo excitação resume, portanto, as três sensações descritas pelos sujeitos: o bem-estar, o prazer e a diversão.

A valorização conferida a essas sensações permite-nos ainda concluir que as atividades por si só não são suficientes para proporcionarem o lazer. Para os adolescentes, ele pode ser vivenciado de diferentes formas, mas seu alcance depende principalmente das pessoas com quem compartilham o momento: "É legal estar com os amigos, mesmo que seja fazendo alguma coisa meio chata" (G2P2). Esse dado vai ao encontro dos resultados encontrados por Sarriera, Paradiso, Marques, Hermel e Coelho (2007). Os fatores essenciais para o lazer ou para a excitação máxima promovida por ele são os amigos, a família, o esporte e também o tempo livre, momento em que ocorrem as socializações. 


\section{Categoria 4 - Lazer como liberdade (às vezes controlada)}

Outra característica essencial para explicar o lazer para os participantes é a liberdade; a possibilidade de fazer o que se quer, o que se gosta e de relativizar as imposições sociais durante sua vivência. Se a liberdade de escolha não parece significar o tempo livre, os dados indicam que para a compreensão do lazer ela é fundamental: "(O lazer) é um tempo livre que você usa para se divertir, para fazer o que você gosta... Pensando em você e não nos outros ou nas suas obrigações" (G3P3); "O lazer é um momento de autodeterminação. Nele, você escolhe o que quer fazer, como quer agir. É um momento totalmente seu, livre (G1P5)”.

Dessa forma, observamos que a liberdade, fruto da vivência do lazer, possibilita aos adolescentes alcançar um momento de "autoderterminação", ou seja, de fazer valer suas próprias vontades, desvencilhando-se, ainda que parcialmente, das expectativas sociais, preocupações e obrigações rotineiras. Essas representações diferenciam-se daquelas que se referem ao tempo livre e reforçam a importância, ressaltada por Munne e Codina (2002), de se viver o lazer de forma autocondicionada, limitando as pressões sociais e garantindo a liberdade.

Contudo, mesmo tendo a liberdade como uma representação social de lazer e reconhecendo que o autocondicionamento se sobressaia em relação ao heterocondicionamento, as interferências externas não deixam de existir e de atuar em suas escolhas. De acordo com os participantes, fatores como gênero, autoridade dos pais, (in)segurança pública e aspectos contextuais (como grupos sociais) interferem diretamente nas suas vivências autônomas de lazer.

Em relação ao gênero, eles afirmaram que apesar de atualmente observarem uma tendência para a igualdade, os padrões de lazer de meninos e meninas ainda são diferentes em virtude de preconceitos perpetuados, principalmente, na educação familiar.

Na nossa criação, meninas não podem falar sobre sexo. A gente é bem mais oprimida ... Se um menino pedir ao pai uma Playboy, vai ser a coisa mais normal do universo; se a menina for vista em um site erótico, é a Terceira Guerra Mundial! Ela vai ser espancada, vai para a igreja, vai ser mandada para o outro continente! (G2P1)

As consequências da diferenciação das vivências do lazer por gênero são históricas e, além de serem sentidas diretamente por elas, são relatadas em investigações científicas (Brenner et al., 2008; Nodari et al., 2016; Oliveira \& Rosa, 2016;). A maior frequência de atividades realizadas em ambientes domésticos, a prática reduzida de esporte e o maior controle de seus comportamentos precisam ser revistos. Caso isso não ocorra, corre-se o risco de prejudicar o desenvolvimento de autonomias, a descoberta da sexualidade, o autoconhecimento e os aspectos físicos e emocionais diretamente ligados à prática esportiva (Oliveira, Nodari, \& Rosa, 2018).

Em relação ao heterocondicionamento provocado pela autoridade dos pais e da insegurança, em virtude da violência, falas como a que segue foram recorrentes:

Às vezes (a limitação) não é nem pelo tempo, é porque os pais não deixam, ou porque é perigoso. Por exemplo, eu gosto de sair andando de bicicleta. Só que eu não posso fazer isso qualquer hora, em qualquer lugar. O ambiente acaba limitando muito o lazer. (G2P3) 
A insegurança e a crença na violência principalmente por parte dos pais são apontadas como resultado de um processo que envolve diversos fatores. É como se os adolescentes reconhecessem que as regras impostas por eles refletissem as ideias veiculadas na mídia e convenientemente aceitas pela sociedade, para atuarem no controle do comportamento e da liberdade juvenil: "Os jornais ajudam muito para isso. Você só vê assalto, estupro, morte. É como se a forma de controlar a gente é falando que eles (os pais) estão protegendo a gente (G2 $\mathrm{P} 1)$ )".

Os participantes pontuaram também a influência que seus gostos e vontades sofrem de acordo com o meio em que vivem. Referindo-se a eles mesmos, os adolescentes citaram as influências do grupo, da moda, da educação e da mídia em seu lazer: "Depende do que acontece fora. Tipo, influência da mídia. Coisas que eles mostram que faz parte da diversão, as pessoas acabam fazendo. Isso também influencia (G3P2)". Observamos, assim, a percepção dos adolescentes sobre o caráter social do lazer, ou seja, o reconhecimento de que este aspecto da vida não se encontra isolado dos contextos e dos grupos a qual pertencem. Essa ideia retoma a teoria de Elias e Dunning (1992) e Munné e Codina (1992) e os achados de Brenner et al. (2008), que reforçam a intrínseca associação entre as vivências de lazer e a sociedade da qual se faz parte e se constrói.

É preciso que se ressalte, todavia, que essas interferências e limitações à vivência do lazer não impedem que a liberdade permaneça sendo percebida como tal, como um elemento importante para a caracterização do fenômeno estudado e para sua diferenciação em relação às demais atividades rotineiras. Ou seja, o lazer proporciona uma percepção de liberdade, mesmo que parcial, diferenciando-se das vivências e atividades cotidianas e mantendo um equilíbrio positivo entre o auto e o heterocondicionamento.

\section{Categoria 5 - Lazer espontâneo e lazer obrigatório}

A noção de lazer para os participantes também revelou estar embasada em uma diferenciação que o divide em dois tipos. Segundo os adolescentes, o fenômeno pode acontecer em momentos sem programação, vividos especialmente nos finais de semana, promovendo um rompimento com as rotinas e com altos níveis de sensações de bem-estar e divertimento; ou, apesar de menos frequente, durante a realização de uma atividade obrigatória, com tempo de início e término determinados, proporcionando satisfações e prazer em um grau moderado.

Ao descrever essa percepção, o participante G1P4 confere uma nomenclatura autoexplicativa aos dois tipos de lazer: "Você pode dividir esse lazer entre um lazer mais obrigatório e um espontâneo”. O lazer obrigatório seria caracterizado, por exemplo, pelas aulas de vôlei, ginástica e basquete ou pelos trabalhos de escola realizados em horários extracurriculares com os colegas. Ou seja, um lazer constituído por atividades que, apesar de serem compromissos, possibilitam momentos de socialização e de divertimento: "Eu, quando me interesso por alguma matéria (escolar), também considero isso como um lazer” ( $\left.\mathrm{G}_{1} \mathrm{P}_{2}\right)$.

Essa classificação definida pelos sujeitos também encontra um equivalente nos trabalhos teóricos. O que os adolescentes denominaram de lazer obrigatório é descrito por autores como semilazer (Bonato et al., 2012) e explicado a partir da variação dos níveis de excitação que pode proporcionar (Elias \& Dunning, 1992), englobando atividades que unem obrigatoriedade e prazer. 
Já o "lazer espontâneo" seria aquele que para os adolescentes caracteriza-se por ser diferente das atividades corriqueiras, por fugir dos padrões do dia a dia, estar associado ao inesperado e por proporcionar níveis de bem-estar, prazer e diversão que nenhuma atividade com caráter de obrigação consegue oferecer. Por seguir esse formato, o lazer espontâneo está associado aos fins de semana e aos momentos que rompem com o que é rotineiro e programado: "O lazer é espontâneo, não está programado. Além desse lazer que é de ler e de estudar, o lazer meio que surge. Você não tem uma rotina de lazer, uma rotina de final de semana ( $\left.\mathrm{G}_{1} \mathrm{P}_{4}\right)$ “.

Contudo, é preciso ficar claro que o dia da semana não é um ponto determinante, mas apenas um dos diversos fatores que estimulam a vivência do lazer (espontâneo). Para os participantes, o sábado e o domingo não são sinônimos de lazer, assim como os dias úteis não impossibilitam que ele aconteça. Todavia, entende-se que as realidades que envolvem as rotinas de segunda a sexta dificultam a sua ocorrência, principalmente nos moldes do lazer espontâneo.

\section{Categoria 6 - Os (não) limites do lazer}

Os grupos focais também revelaram que o lazer não é considerado pelos participantes como uma prática na qual tudo é permitido e aceitável. A conscientização de que vivemos em sociedade, de que nossas ações interferem na vida dos outros, e de que a nossa saúde e bem-estar exigem atenção ficou perceptível nas colocações dos adolescentes: "O lazer só não pode ser risco. Às vezes, o que é lazer para você pode afetar outra pessoa. Então, quando você pensa em lazer, você tem que pensar no todo, pois você vive em sociedade” (G3P2).

Os estudantes ainda demonstraram perceber a complexidade envolvida na definição dos limites para o lazer. Eles buscaram ponderar o que em geral se aceita como certo ou errado, considerando interesses, relativismos e influências culturais envolvidas no processo:

Cada lazer é muito diferente, depende da cultura em que se vive. E não existe um valor universal do que é bom ou ruim. Porque se vocêpensar que o que está na lei é o que é bom... é uma coisa meio confusa, pois o que está na lei também é subjetivo, os caras escolheram aquilo lá. Você escolhe um representante, mas o cara vai fazer a lei baseado na cultura dele. Por que a cultura dele seria melhor que a cultura de um indio? $\left(\mathrm{G}_{1} \mathrm{P} 2\right)$

O seu lazer pode ser fumar maconha e para outras pessoas pode ser jogar videogame. Eu acho que, para aquela pessoa, o lazer certo vai ser fumar maconha, e o errado, jogar videogame. O ensinamento da sociedade delimita o certo e o errado, mas cada pessoa tem o seu momento de lazer bom e de lazer menos bom. ( $\mathrm{G} 1 \mathrm{P} 4)$

Apesar dessas reflexões que relativizam os conceitos socialmente aceitos de "lazer bom" e de "lazer ruim", verificamos que os adolescentes possuem um modo próprio de classificar e entender os diferentes tipos de lazer. Para alguns deles, o "lazer ruim" está mais frequentemente relacionado aos atos de fumar maconha, fumar cigarro, beber bebidas alcoólicas e de jogar videogame ou computador em excesso. Esses elementos aparecem objetificando o lazer considerado inadequado: "Mesmo se não existisse proibição para fumar maconha, eu acho que ela está te matando. Ela poderia até ser legalizada, mas a pessoa está se prejudicando" (G2P4). 
Essas atividades são exatamente aquelas que aparecem nos resultados de estudos sobre comportamentos de risco, especialmente, associados ao lazer e ao tempo livre (Chimeli et al., 2016; Sarriera et al., 2007). Apesar delas não terem aparecido nos dados como definidoras do lazer de modo geral, ou ilustrando as ações realizadas pelos próprios participantes - exceto o ato de jogar em excesso -, ficou explícita a relação referente à representação social periférica que o lazer de adolescentes, eventualmente, pode ter com fumar maconha, beber e jogar.

Ainda que os sujeitos tenham associado essas práticas mais frequentemente ao lazer "ruim", outros fatores reforçaram a necessidade de se dar atenção à questão, como pela valorização que eles conferem às novas e diferentes experiências e pelo o prazer as ações proibidas podem proporcionar: "Às vezes, quando você quer muito fazer alguma coisa que as pessoas não deixam, você deveria se permitir fazer isso, mesmo que seja uma coisa ruim, para você sentir na cara o que vai acontecer... O proibido é mais gostoso" (G2P4).

É preciso reconhecer que apesar das atividades de risco não terem aparecido como elementos centrais, elas estão possivelmente presentes nesse universo, e podem se mostrar como opção para a vivência de novas experiências e superação dos limites impostos pelos pais. Assim, a perspectiva do risco faz-se coerente, mas não deve ser assumida como a principal, considerando que as atividades mencionadas nesse sentido se apresentam, apenas, como uma representação periférica. Além disso, é importante pontuar que a vivência do risco entre os adolescentes e jovens nem sempre é negativa. Muitas vezes ela traz um extravasamento emocional desejado, a partir de práticas de atividades com risco controlado (Spink, Aragaki, \& Alves, 2005); e, em alguns casos, podem ser fundamentais para que os indivíduos testem seus limites, sintam-se vivos e vivam rituais próprios da passagem da juventude para a vida adulta (Le Breton, 2012).

\section{Considerações finais}

A investigação possibilitou identificar diversos aspectos das representações sociais do lazer e do tempo livre de adolescentes de classe média. Se ora os participantes os consideram como momentos de liberdade, autonomia, prazer, sociabilidade; as noções de obrigação, de estudo e descanso para a prática da produção também se fazem presentes. Essas contradições, que no âmbito da TRS já são previsíveis (Abric, 2001), reforçam a dualidade e o conflito que a sociedade contemporânea tem vivenciado: trabalhar ou divertir-se? Manter a lógica da produção e do consumo ou optar por uma vida mais simples? Nesse sentido, observou-se a ancoragem das representações dos participantes nos valores que vigoram no contexto em que vivem.

Essa constatação refuta as ideias simplistas que remetem o lazer e o tempo livre de jovens e adolescentes apenas às noções negativas de desocupação, perigo, falta de limites e drogas. Os resultados demonstram que para os participantes esses podem ser, sim, alguns elementos periféricos de suas representações, mas no núcleo central possivelmente estão a prática esportiva e as vivências com os amigos e com os pais. Além disso, deve-se considerar que o próprio risco (risco-desejado) pode ser fundamental para promover um ritual de passagem dos jovens e adolescentes para a vida adulta e para a busca de reconhecimento de seus limites e de extravasamento emocional (Le Breton, 2012; Spink, Aragaki, \& Alves, 2005). 
Especialmente sobre o lazer feminino, ressalta-se o entrave que as adolescentes encontram para superar os estereótipos limitadores conferidos a elas. As participantes reforçaram que a ideia de serem do "sexo frágil" ainda as aprisionam e dificultam suas vivências sexuais e a prática esportiva. Por outro lado, para os meninos, o destaque negativo foi dado para o ato de jogar desmedidamente no computador e no videogame. Para eles, a falta do que fazer e o vício acarretam em muita "perda de tempo". Diante dos resultados, acredita-se que as negatividades do tempo livre de adolescentes de classe média estejam principalmente em casa, e em virtude da escassa discussão sobre a liberdade que essas esferas tendem e devem proporcionar.

Buscando uma reflexão sobre a melhoria do aproveitamento do lazer e do tempo livre para os participantes, sugere-se maior atenção a pouca discussão sobre o assunto; a significativa penetração da lógica capitalista na representação dos dois fenômenos; e a escassa autonomia e liberdade conferida aos adolescentes nesses momentos próprios de extravasamento emocional e autoconhecimento. Ou seja, investir no lazer e no tempo livre deve significar fazer com que esses momentos existam, de fato, na vivência adolescente; que superem as obrigações de produção; e que sejam incentivadores para que esses indivíduos explorem seus talentos, criatividades, autonomias e o ócio.

\section{Referências}

Abramo, H. W. (2007). Considerações sobre a tematização social da juventude no Brasil. In O. Fávero, M. P. Spósito, P. Carrano, \& R. R. Novaes (Orgs.), Juventude e Contemporaneidade (pp. 73-90). Brasília, DF: UNESCO; MEC; ANPEd.

Abramo, H. W. (2008). Condição juvenil no Brasil contemporâneo. In H. W. Abramo \& P. P. M. Branco (Orgs.), Retratos da juventude brasileira (pp. 37-72). São Paulo: Fundação Perseu Abramo.

Abric, J. C. (2001). Prácticas sociales y representaciones. México: Ediciones Coyoacán. Adorno, T. (2002). Tempo Livre. In J. M. B. Almeida (Comp.), Indústria cultural e sociedade (pp. 62-70). São Paulo: Paz e Terra.

Amra, B., Shahsavarib, A., Shayan-Moghadamb, R., Mirh elia, O., Moradi-Khaniabadib, B., Bazukara, M., Yadollahi-Farsani, A., \& Kelishadi, R. (2017). The association of sleep and late-night cellphone use among adolescente. Jornal de Pediatria, 93(6), 560-567.

Aquino, C. A. B \& Martins, J. C. O. (2007). Ócio, lazer e tempo livre na sociedade do consumo e do trabalho. Revista Mal-Estar e Subjetividade, 7(2), 479-500.

Bardlin, L. (2007). Análise de conteúdo. Lisboa: Edições 70.

Bonato, T. N, Sarriera, J. C., \& Wagner, A. (2012). O lazer na Adolescência. In J. C. Sarriera \& A. C. Paradiso (Orgs.), Tempo livre e lazer na adolescência: Promoção da saúde, intervenção e pesquisa (pp. 97-123). Porto Alegre: Sulina.

Brenner, A. K, Dayrell, J., \& Carrano, P. (2008). Juventude brasileira: culturas do lazer e do tempo livre. In N. Teles (Org.), Um olhar sobre o jovem no Brasil (pp. 29-44) Brasília, DF: Ministério da Saúde. 
Capelini, C. R. L. \& Dias, R. G. (2017). Qualidade de sono na coordenação geral de adolescentes entre 12 e 14 anos. Do corpo: Ciências e Artes, 7(1), 31- 44.

Cardoso, A. C. M. (2007). Tempos de trabalho, tempos de não trabalho: Vivências cotidianas de trabalhadores. Tese de Doutorado, Programa de Pós-graduação em Sociologia, Universidade de São Paulo, São Paulo.

Chimeli, I. V., Nogueira, M. J., Pimenta, D. N., \& Schall, V. T. (2016). A abstração do risco e a concretude dos sujeitos: uma reflexão sobre os comportamentos de risco no contexto da adolescência. Physis: Revista de Saúde Coletiva, 26(2), 399-415.

Elias, N. \& Dunning, E. (1992). A busca da excitação. Lisboa: Difel.

Franch, M. (2000). Tardes ao léu: um ensaio etnográfico sobre o tempo livre entre jovens de periferia. Dissertação de Mestrado, Programa de Pós-graduação em Antropologia, Universidade Federal de Pernambuco, Recife, PE.

Jodelet, D. (2011). Ponto de vista: Sobre o movimento das representações sociais na comunidade científica brasileira. Temas em Psicologia, 12(1), 19-26.

Le Breton, D. (2012). O risco deliberado: Sobre o sofrimento dos adolescentes. Revista de Ciências Sociais, 37, 33-44.

Martins, M. P., Trimdade, Z. A., Menandlro, M. C. S., \& Nascimento, C. R. R (2014). Representações sociais e vivências de lazer na juventude. Psicologia e Saber Social, 3(1), 41-54.

Moscovici, S. (1978). A representação social da psicanálise. Rio de janeiro: Zahar.

Moscovici, S. (2003). O fenômeno das representações sociais. In Representações sociais: investigações em psicologia social (pp. 29-109). Petrópolis, RJ: Vozes.

Munné, F. \& Codina, N. (1992). Algunos aspectos del impacto tecnológico en el consumo infatil del ocio. Anuario de Psicología, 53(2), 113-125.

Nóbrega, D. O., Andrade, E. R. G., \& Melo, E. S. N. (2016). Pesquisa com grupo focal: Contribuições ao estudo das representações sociais. Psicologia \& Sociedade, 28(3), 433-441.

Nodari, M. P. M., Rosa, E. M., Nascimento, C. R. R., \& Guerra, W. M. (2016). Os usos do tempo livre entre jovens de classes populares. Psicologia: Teoria e Pesquisa, 32(4), 1-9.

Nunes, M. F. O., Pires, J. G., Azevedo, C., \& Hutz, C. S. (2014). Satisfação e autonomia nas atividades de lazer entre universitários. Psicologia: Teoria e Prática. 16(1), 91-103.

Oliveira, E. F. \& Rosa, E. M. (2016). Representações sociais de lazer e de tempo livre: vivências e sociabilidades de jovens universitárias. Psicologia e Saber Social, 5(1), 46-67.

Oliveira, E. F., Nodari, M. P. M., \& Rosa, E. M. (2018). Conhecendo jovens de classe média: Um estudo sobre suas práticas de lazer e de tempo livre. In E. M. Rosa, C. R. R. Nascimento, \& D. B. Nascimento (Orgs.), Jovens e Adolescentes: Contextos e vivências no Espírito Santo (pp. 87-112). Vitória: GM.

Sá, C. P. (1998). A construção do objeto de pesquisa em representações sociais. Rio de Janeiro: EdUERJ.

Stengel, M. \& Dayrell, J. T. (2017). Produção sobre adolescência/ juventude na pós-graduação da Psicologia no Brasil. DESidades, 14(5), 18-29.

Spink, M. J. P., Aragaki, S. S., \& Alves, M. P. (2005). Da exacerbação dos sentidos no encontro com a natureza: Contrastando esportes radicais com turismo de aventura. Psicologia: Reflexão e Crítica, 18(1), 26-38.1

Sarriera, J. C., Paradiso, A. C., Marques, L. F., Hermel, J. S., \& Coelho, R. P. S. (2007). Significado do tempo livre para adolescentes de classe popular. Psicologia Ciência e Profissão, 27(4), 718-729. 


\section{ELISA FABRIS DE OLIVEIRA}

\section{http://orcid.org/OOOO-0002-5177-1847}

É doutoranda e mestre em Psicologia e graduada em Comunicação Social pela Universidade Federal do Espírito Santo; bolsista da Coordenação de Aperfeiçoamento de Pessoal de Nível Superior (Capes) entre 2014 e 2015; professora da Faculdade de Ensino Superior de Linhares.

Endereço: Faculdade de Ensino Superior de Linhares: Av. Presidente Costa e Silva, 177, Novo Horizonte, Linhares-ES, CEP 29902-120.

E-mail: elisa.fbrs@gmail.com

\section{EDINETE MARIA ROSA}

http://orcid.org/orcid 0000-0003-4279-8308

É doutora em Psicologia; bolsista pesquisadora capixaba (FAPES) entre $2013 \mathrm{e}$ 2016; professora do Departamento de Psicologia Social e do Desenvolvimento da Universidade Federal do Espírito Santo; professora do Programa de Pósgraduação em Psicologia da Universidade Federal do Espírito Santo, Vitória. E-mail: edineter@gmail.com

\begin{tabular}{|c|c|}
\hline Histórico & $\begin{array}{l}\text { Submissão: 16/03/2018 } \\
\text { Revisão: } 15 / 02 / 2019 \\
\text { Aceite: } 14 / 03 / 2019\end{array}$ \\
\hline Contribuição dos autores & $\begin{array}{l}\text { Concepção: Elisa e Edinete } \\
\text { Coleta de dados: Elisa } \\
\text { Análise de dados: E.F.O.; E.M.R. } \\
\text { Elaboração do manuscrito: E.F.O. } \\
\text { Crítico revisões de conteúdo intelectual importante: } \\
\text { E.M.R. } \\
\text { Final aprovação do manuscrito: E.F.O.; E.M.R. }\end{array}$ \\
\hline Financiamento & $\begin{array}{l}\text { Elisa Fabris de Oliveira: Bolsista Coordenação de Aper- } \\
\text { feiçoamento de Pessoal de Ensino Superior (CAPES), } \\
\text { Programa Demanda Social (DS). } \\
\text { Edinete Maria Rosa: Bolsista de Produtividade do CNPq }\end{array}$ \\
\hline $\begin{array}{l}\text { Consentimento de uso de } \\
\text { imagem }\end{array}$ & $\begin{array}{l}\text { Foi obtido o consentimento escrito dos participantes e/ } \\
\text { ou do detentor dos direitos autorais sobre a imagem. } \\
\text { Sim. Por meio dos Termos de Consentimento e Assenti- } \\
\text { mento Livre e Esclarecido. }\end{array}$ \\
\hline $\begin{array}{l}\text { Aprovação, ética e } \\
\text { consentimento }\end{array}$ & $\begin{array}{l}\text { O estudo foi aprovado pelo Comitê de Ética da Univer- } \\
\text { sidade Federal do Espírito Santo, com o CAAE número } \\
286995 \text { 14.0.0000.5542. }\end{array}$ \\
\hline
\end{tabular}

